\title{
Elevated levels of plasma lactate dehydrogenase is an unfavorable prognostic factor in patients with epidermal growth factor receptor mutation-positive non-small cell lung cancer, receiving treatment with gefitinib or erlotinib
}

\author{
MINEHIKO INOMATA ${ }^{1}$, RYUJI HAYASHI ${ }^{1}$, HIROAKI TANAKA ${ }^{1}$, KAZUKI SHIMOKAWA ${ }^{1}$, KOTARO TOKUI $^{1}$, \\ CHIHIRO TAKA ${ }^{1}$, SEISUKE OKAZAWA ${ }^{1}$, KENTA KAMBARA ${ }^{1}$, TOMOMI ICHIKAWA ${ }^{1}$, TORU YAMADA ${ }^{1}$, \\ TOSHIRO MIWA ${ }^{1}$, TATSUHIKO KASHII ${ }^{2}$, SHOKO MATSUI $^{3}$ and KAZUYUKI TOBE ${ }^{1}$ \\ ${ }^{1}$ First Department of Internal Medicine, Faculty of Medicine, University of Toyama; ${ }^{2}$ Department of Medical Oncology, \\ Toyama University Hospital; ${ }^{3}$ Health Administration Center, University of Toyama, Toyama 930-0194, Japan
}

Received August 31, 2015; Accepted February 3, 2016

DOI: $10.3892 / \mathrm{mco} .2016 .779$

\begin{abstract}
Treatment with epidermal growth factor receptor-tyrosine kinase inhibitors (EGFR-TKIs) has been shown to prolong survival in patients with EGFR mutation-positive non-small cell lung cancer (NSCLC). The present study performed a retrospective analysis to investigate the association between the plasma lactate dehydrogenase (LDH) levels and survival in patients with EGFR mutation-positive NSCLC receiving treatment with EGFR-TKIs. The medical charts of patients with EGFR mutation-positive NSCLC who were receiving treatment with EGFR-TKIs at Toyama University Hospital between 2007 and 2014 were assessed. The data from 65 patients were included in the analysis. Patients with higher plasma LDH levels exhibited shorter progression-free survival (6.2 vs. 13.2 months; $\mathrm{P}<0.01)$ and overall survival (10.5 vs. 36.1 months; $\mathrm{P}<0.01)$ periods compared with patients with lower plasma LDH levels. A Cox proportional hazards model identified that the plasma $\mathrm{LDH}$ level was associated with the progression-free survival $(\mathrm{P}=0.05)$ and overall survival $(\mathrm{P}<0.01)$. An association was demonstrated between the pretreatment plasma LDH level and the survival in patients with EGFR mutation-positive NSCLC receiving treatment with EGFR-TKIs. Close observation is required in EGFR mutation-positive NSCLC patients exhibiting high plasma LDH levels following the initiation of treatment with EGFR-TKIs.
\end{abstract}

Correspondence to: Dr Minehiko Inomata, First Department of Internal Medicine, Faculty of Medicine, University of Toyama, 2630 Sugitani, Toyama 930-0194, Japan

E-mail: cxhcw543@gmail.com

Key words: epidermal growth factor receptor, lactate dehydrogenase, lung cancer, prognosis, tyrosine kinase inhibitor

\section{Introduction}

Lung cancer is a leading cause of mortality worldwide. Although treatment with epidermal growth factor receptor-tyrosine kinase inhibitors (EGFR-TKIs) has been reported to prolong the survival in patients with EGFR mutation-positive non-small cell lung cancer (NSCLC) (1-3), the survival period varies widely in individual patients receiving EGFR-TKI treatment.

Our previous study reported the existence of an association between the pre-treatment plasma neuron-specific enolase level and the patient survival in EGFR mutation-positive NSCLC patients initiated on gefitinib treatment (4). Neuron-specific enolase is a marker of neuroendocrine tumors, including small cell lung cancer, and functions as a glycolytic enzyme. Lactate dehydrogenase (LDH), also an enzyme contributing to anaerobic glycolysis, has been reported as a prognostic factor in patients with various malignant tumors, including lung cancer (5-8). The association between the plasma LDH level and tumor hypoxia is considered as one of the mechanisms underlying this linkage (6-8). However, the impact of the pre-treatment plasma LDH level on the survival in patients with EGFR mutation-positive NSCLC receiving treatment with EGFR-TKIs remains to be elucidated.

For patients with lung cancer initiated on treatment with EGFR-TKIs, investigation of the prognostic factors and identification of patients with a poor prognosis are important for planning the appropriate follow-up schedule, and may also contribute to the establishment of novel treatment strategies. The present study performed a retrospective analysis to investigate the association between the plasma LDH levels and survival in EGFR mutation-positive NSCLC patients receiving treatment with EGFR-TKIs.

\section{Patients and methods}

Patient selection and evaluation. The present study retrospectively reviewed the medical charts of patients with lung cancer 
receiving treatment at Toyama University Hospital (Toyama, Japan) between 2007 and 2014. The inclusion criteria were as follows: i) Cytologically or histologically confirmed NSCLC; ii) tumor positive for EGFR gene mutations, with the exception of the T790M mutation; iii) patients receiving treatment with EGFR-TKIs. Patients with a previous history of treatment with EGFR-TKIs were excluded from the analysis.

The following patient data was collected: Age, gender, number of treatment regimens received previously, disease stage, tumor EGFR mutation status, patient performance status (PS), smoking history and presence/absence of distant metastasis. Exon 19 deletions and the exon 21 point mutation of L858R in the EGFR gene were classified as common mutations, while any other mutations were classified as uncommon mutations. The disease stage was classified as stage III/IV or postoperative recurrence. Presence/absence of metastatic lesions was determined by imaging examinations, including computed tomography, magnetic resonance imaging and/or scintigraphy, regardless of the cytological or histological findings. The present study was performed with the approval of the Ethics Committee of the University of Toyama (approval no. 26-158).

Statistical analysis. Survival curves were drawn according to the Kaplan-Meier method. Progression-free survival (PFS) was calculated from the date on which the EGFR-TKI administration was initiated until the date on which disease progression was first documented or the date of mortality due to any cause, and censored at the last visit at which no disease progression was observed. The overall survival (OS) was calculated from the date on which the EGFR-TKI administration was initiated until the date of mortality due to any cause, and censored at the last visit at which the patient remained alive. The association between the survival and the patient clinical characteristics was analyzed by the log-rank test. With regards to the analysis regarding the LDH level, the patients were dichotomized into two groups, according to the median LDH level. The independent association between each variable and the survival were analyzed using a Cox proportional hazards model. The variables with a P-value $<0.2$ by the log-rank test were entered as independent variables into the Cox proportional hazards model.

\section{Results}

Patient characteristics. Table I lists the patient characteristics. A total of 65 patients fulfilled the criteria and were included in the analysis. Of these, 41 patients who were receiving treatment with gefitinib were also enrolled into our previous study (4). Female patients were slightly dominant, accounting for $53.8 \%$ of the population. The median (range) age of the patients was 68 (49-87) years, and 52.3\% were < 70 -years-old. The majority of the patients were treated with gefitinib and $28.5 \%$ of patients were treated with erlotinib. The majority of patients $(90.8 \%)$ exhibited tumors harboring common EGFR gene mutations. The plasma $\mathrm{LDH}$ levels ranged between 118 and 1,680 IU/1 (median value, 208 IU/1). Disease stage, PS, smoking history, liver metastases and pleural effusion were imbalanced between the two groups.

Survival. Fig. 1 reveals the Kaplan-Meier survival curves for the PFS and OS in the patient groups divided by the plasma
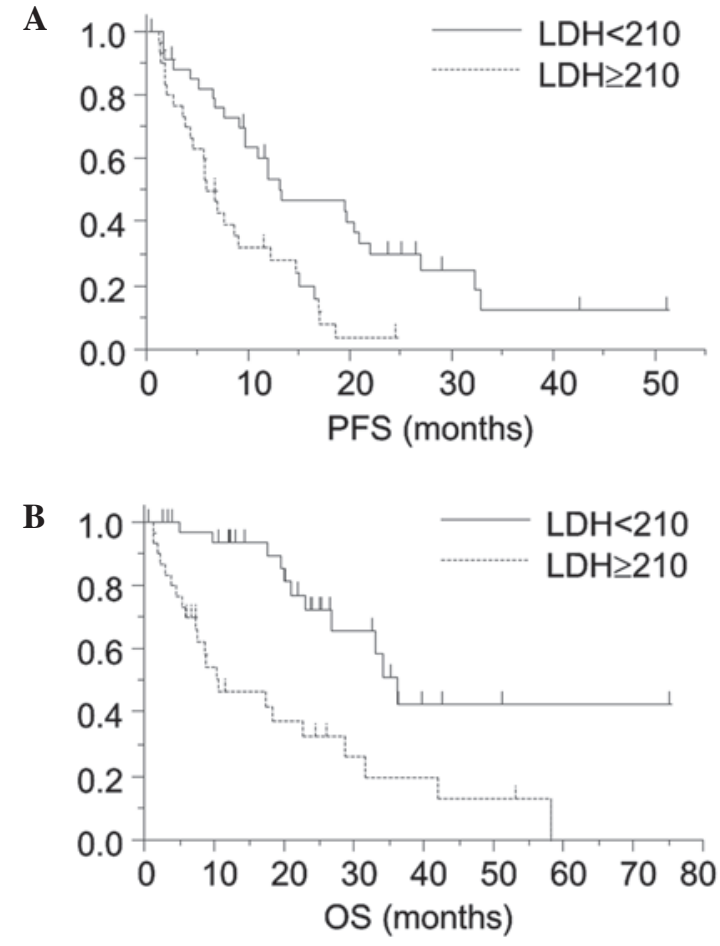

Figure 1. Kaplan-Meier curve for each patient group divided according to the plasma LDH level (solid line, $\mathrm{LDH}<210$; dashed line, $\mathrm{LDH} \geq 210$ ). The patient group with a higher plasma LDH level had (A) shorter PFS $(\mathrm{P}<0.01)$ and (B) OS $(\mathrm{P}<0.01)$ periods. $\mathrm{LDH}$, lactate dehydrogenase; $\mathrm{PFS}$, progression-free survival; OS, overall survival.

LDH level of 210 IU/l. Significant differences in the PFS (6.2 vs. 13.2 months; $\mathrm{P}<0.01)$ and $\mathrm{OS}(10.5$ vs. 36.1 months; $\mathrm{P}<0.01)$ were observed between the high-LDH and low-LDH groups.

The log-rank test revealed that the P-values for the disease stage $(\mathrm{P}=0.02)$, EGFR mutation status $(\mathrm{P}=0.17)$, PS $(\mathrm{P}=0.01)$, presence/absence of brain metastasis $(\mathrm{P}<0.01)$, presence/absence of liver metastasis $(\mathrm{P}=0.10)$, presence/absence of pleural effusion $(\mathrm{P}=0.12)$ and the plasma LDH level $(\mathrm{P}<0.01)$ were determined to be $<0.2$, and these variables were entered into the Cox proportional hazards model as independent variables. The $\mathrm{P}$-value for gender $(\mathrm{P}=0.37)$, age $(\mathrm{P}=0.25)$, type of EGFR-TKI $(\mathrm{P}=0.60)$, number of previous treatment regimens $(\mathrm{P}=0.91)$, smoking history $(\mathrm{P}=0.43)$, presence/absence of metastasis to the lung $(\mathrm{P}=0.83)$, bone $(\mathrm{P}=0.90)$ and adrenal gland $(P=0.95)$ were $>0.2$. Table II shows the results of the analysis performed using the Cox proportional hazards model to assess the association between each variable and the PFS. The analysis identified that the EGFR status $(\mathrm{P}=0.03)$, presence/absence of brain metastasis $(\mathrm{P}<0.01)$ and the plasma LDH level $(\mathrm{P}=0.05)$ were associated with the PFS.

With regards to the OS, the P-values for the disease stage $(\mathrm{P}=0.07)$, EGFR mutation status $(\mathrm{P}=0.07)$, $\mathrm{PS}(\mathrm{P}<0.01)$, presence/absence of pleural effusion $(\mathrm{P}=0.01)$ and plasma $\mathrm{LDH}$ level $(\mathrm{P}<0.01)$ were $<0.2$, and these were entered into the Cox proportional hazards model as independent variables. The $\mathrm{P}$-value for gender $(\mathrm{P}=0.29)$, age $(\mathrm{P}=0.94)$, type of EGFR-TKI $(\mathrm{P}=0.80)$, number of previous treatment regimens $(\mathrm{P}=0.46)$, smoking history $(\mathrm{P}=0.62)$, and the presence/absence of metastasis to the brain $(\mathrm{P}=0.34)$, liver $(\mathrm{P}=0.36)$, lung $(\mathrm{P}=0.61)$, bone 
Table I. Patient characteristics.

\begin{tabular}{|c|c|c|c|}
\hline Characteristic & $\begin{array}{l}\text { All patients } \\
\quad(\mathrm{n}=65)\end{array}$ & $\begin{array}{l}\text { LDH low } \\
(\mathrm{n}=35)\end{array}$ & $\begin{array}{l}\text { LDH high } \\
\quad(\mathrm{n}=30)\end{array}$ \\
\hline \multicolumn{4}{|l|}{ Gender, n (\%) } \\
\hline Male & $30(46.2)$ & $19(54.3)$ & $11(36.7)$ \\
\hline Female & $35(53.8)$ & $16(45.7)$ & $19(63.3)$ \\
\hline \multicolumn{4}{|l|}{ Age, n (\%) } \\
\hline$<70$ & $34(52.3)$ & $18(51.4)$ & $16(53.3)$ \\
\hline$\geq 70$ & $31(47.7)$ & 17 (48.6) & $14(46.7)$ \\
\hline \multicolumn{4}{|c|}{ EGFR-TKI, n (\%) } \\
\hline Gefitinib & $53(81.5)$ & $28(80.0)$ & $25(83.3)$ \\
\hline Erlotinib & $12(28.5)$ & $7(20.0)$ & $5(16.7)$ \\
\hline \multicolumn{4}{|c|}{ Prior regimen, $\mathrm{n}(\%)$} \\
\hline 0 & $49(75.4)$ & $25(71.4)$ & $24(80.0)$ \\
\hline$\geq 1$ & $16(24.7)$ & $10(28.6)$ & $6(20.0)$ \\
\hline \multicolumn{4}{|l|}{ Stage, n (\%) } \\
\hline III/IV & $50(76.9)$ & $23(65.7)$ & $27(90.0)$ \\
\hline Recurrence & $15(23.1)$ & $12(34.3)$ & $3(10.0)$ \\
\hline \multicolumn{4}{|c|}{ EGFR status, n (\%) } \\
\hline Common & $59(90.8)$ & $31(88.6)$ & $28(93.3)$ \\
\hline Uncommon & $6(9.2)$ & $4(11.4)$ & $2(6.7)$ \\
\hline \multicolumn{4}{|l|}{$\mathrm{PS}, \mathrm{n}(\%)$} \\
\hline $0-1$ & $45(69.2)$ & $27(77.1)$ & $18(60.0)$ \\
\hline$\geq 2$ & $20(30.8)$ & $8(22.9)$ & $12(40.0)$ \\
\hline \multicolumn{4}{|c|}{ Smoking history, n (\%) } \\
\hline Yes & $31(47.7)$ & $20(57.1)$ & $11(36.7)$ \\
\hline No & $34(52.3)$ & $15(42.9)$ & $19(63.3)$ \\
\hline \multicolumn{4}{|c|}{ Brain metastases, $\mathrm{n}(\%)$} \\
\hline Yes & $19(29.2)$ & $10(28.6)$ & $9(30.0)$ \\
\hline No & $46(70.8)$ & $25(71.4)$ & $21(70.0)$ \\
\hline \multicolumn{4}{|c|}{ Liver metastasis, n (\%) } \\
\hline Yes & $14(21.5)$ & $4(11.4)$ & $10(33.3)$ \\
\hline No & $51(78.5)$ & $31(88.6)$ & $20(66.7)$ \\
\hline \multicolumn{4}{|c|}{ Lung metastasis, n (\%) } \\
\hline Yes & $25(38.5)$ & $12(34.3)$ & $13(43.3)$ \\
\hline No & $40(61.5)$ & $23(65.7)$ & $17(56.7)$ \\
\hline \multicolumn{4}{|c|}{ Adrenal gland metastasis, n (\%) } \\
\hline Yes & $5(7.7)$ & $2(5.7)$ & $3(10.0)$ \\
\hline No & $61(92.3)$ & $33(94.3)$ & $27(90.0)$ \\
\hline \multicolumn{4}{|c|}{ Bone metastasis, n (\%) } \\
\hline Yes & $31(47.7)$ & $15(42.9)$ & $16(53.3)$ \\
\hline No & $34(52.3)$ & $20(57.1)$ & $14(46.7)$ \\
\hline \multicolumn{4}{|c|}{ Pleural effusion, $\mathrm{n}(\%)$} \\
\hline Yes & $30(46.2)$ & $10(28.6)$ & $20(66.7)$ \\
\hline No & $35(53.8)$ & $25(71.4)$ & $10(33.3)$ \\
\hline
\end{tabular}

LDH, lactate dehydrogenase; EGFR-TKI, epidermal growth factor receptor-tyrosine kinase; PS, performance status.

$(\mathrm{P}=0.66)$ and adrenal gland $(\mathrm{P}=0.93)$ were $>0.2$. Table III shows the results of the analysis performed using the Cox proportional hazards model to assess the association between each variable and the OS. The analysis identified that the EGFR status $(\mathrm{P}<0.01)$, PS $(\mathrm{P}=0.03)$ and plasma $\mathrm{LDH}$ level $(\mathrm{P}<0.01)$ were associated with the OS. 
Table II. Analysis using a Cox proportional hazards regression model for assessing the association between the plasma lactate dehydrogenase level and progression-free survival.

\begin{tabular}{lcc}
\hline Variable & HR $(95 \%$ CI $)$ & P-value \\
\hline $\begin{array}{l}\text { Stage } \\
\text { III/IV }\end{array}$ & 0.59 \\
Recurrence & $1.28(0.53-3.31)$ & \\
EGFR status & 1 & 0.03 \\
Common & $0.30(0.11-0.90)$ & \\
Uncommon & 1 & 0.28 \\
PS & & \\
$0-1$ & $0.66(0.32-1.40)$ & $<0.01$ \\
$\geq 2$ & 1 & \\
Brain metastasis & & 0.47 \\
Yes & $3.39(1.56-7.37)$ & \\
No & 1 & 0.19 \\
Liver metastasis & $1.32(0.61-2.70)$ & \\
Yes & 1 & \\
No & $1.74(0.76-3.92)$ & \\
Pleural effusion & 1 & \\
Yes & $0.49(0.24-0.99)$ & \\
No & 1 & \\
LDH & & \\
$<210$ & & \\
$\geq 210$ & & \\
\hline
\end{tabular}

EGFR, epidermal growth factor receptor; LDH, lactate dehydrogenase; PS, performance status; HR, hazard ratio; CI, confidence interval.

Post-progression treatment. In the higherLDH group, 27 patients experienced disease progression, $4(14.8 \%)$ patients were treated with EGFR-TKI re-administration, 5 (18.5\%) were treated with platinum doublet chemotherapy and $5(18.5 \%)$ were treated with single cytotoxic agent. In the lower LDH group, 25 patients experienced disease progression, $3(12.0 \%)$ were treated with EGFR-TKI re-administration, 5 (20.0\%) were treated with platinum doublet chemotherapy and $4(16.0 \%)$ were treated with a single cytotoxic agent.

\section{Discussion}

The present study revealed the existence of a significant association between the pre-treatment plasma LDH level and survival in patients with EGFR mutation-positive NSCLC receiving treatment with EGFR-TKIs. Elevated plasma LDH has been reported to be associated with a poor prognosis in patients with several types of malignancies, including lung cancer, receiving various treatments (5-8). Based on these previous reports, it was considered that the plasma LDH level may serve as a prognostic factor in patients with EGFR mutation-positive NSCLC.

Several mechanisms underlying the association between the serum LDH level and the patient survival have been proposed. $\mathrm{LDH}$ is a glycolytic enzyme that contributes to anaerobic
Table III. Analysis using a Cox proportional hazards regression model for assessing the association between the plasma lactate dehydrogenase level and the overall survival.

\begin{tabular}{lcr}
\hline Variable & HR $(95 \% \mathrm{CI})$ & P-value \\
\hline $\begin{array}{l}\text { Stage } \\
\text { III/IV }\end{array}$ & 0.42 \\
Recurrence & $1.52(0.56-4.80)$ & \\
EGFR status & 1 & $<0.01$ \\
Common & $0.14(0.04-0.49)$ & \\
Uncommon & 1 & 0.03 \\
PS & $0.36(0.14-0.89)$ & \\
$0-1$ & 1 & 0.14 \\
$\geq 2$ & $1.97(0.80-5.11)$ & \\
Pleural effusion & 1 & $<0.01$ \\
Yes & & \\
No & $0.27(0.11-0.61)$ & \\
LDH & 1 & \\
$<210$ & & \\
$\geq 210$ & & \\
\hline
\end{tabular}

EGFR, epidermal growth factor receptor; LDH, lactate dehydrogenase; PS, performance status; HR, hazard ratio; CI, confidence interval.

production of adenosine triphosphate, and the increased production of $\mathrm{LDH}$ can be a direct marker of severe tumor hypoxia. $\mathrm{LDH}-5$, one of the isoenzymes of $\mathrm{LDH}$, is induced by hypoxia-inducible factor- $1 \alpha$ in the hypoxic environment of the tumor; therefore, high plasma LDH may reflect an upregulated hypoxia inducible factor- $1 \alpha$-molecular cascade $(7,8)$. Findings lending support to the above-mentioned mechanisms were reported by Koukourakis et al (7) who demonstrated that the tumor LDH-5 expression was associated with that of hypoxia-inducible factor and vascular endothelial growth factor. In addition, LDH activity results in acidification of the extracellular space through the production of lactic acid, which may be associated with an increased invasive ability and angiogenic capability of tumors (6-8).

It is possible that the association between plasma LDH level and survival demonstrated in the present study partly resulted from the activity of VEGF. The additional efficacy of bevacizumab on erlotinib in patients with NSCLC harboring EGFR gene mutation (9) suggests that VEGF activity influences patient survival or efficacy of EGFR-TKI, although the association between VEGF expression and the patient survival treated with EGFR-TKI remains to be elucidated.

The present study was retrospective in nature and the sample size was small. Although multivariate analyses were performed, it may be difficult to completely exclude the possible existence of confounding factors affecting patient survival. Furthermore, it was not confirmed whether the plasma LDH level may be a predictive factor due to the small sample size and retrospective design of this study.

In conclusion, the results of the present study indicated the existence of an association between the pretreatment plasma 
LDH level and survival in EGFR mutation-positive NSCLC patients receiving treatment with EGFR-TKIs, as previous studies had suggested the existence of a population with a poor prognosis even among these patients. Evaluation of the pretreatment plasma LDH level may contribute to follow-up planning in patients receiving treatment with EGFR-TKIs, and the establishment of a treatment strategy for the population with a poor prognosis is expected.

\section{References}

1. Mok TS, Wu YL, Thongprasert S, Yang CH, Chu DT, Saijo N, Sunpaweravong $\mathrm{P}$, Han B, Margono B, Ichinose $\mathrm{Y}$, et al: Gefitinib or carboplatin-paclitaxel in pulmonary adenocarcinoma. N Engl J Med 361: 947-957, 2009.

2. Maemondo M, Inoue A, Kobayashi K, Sugawara S, Oizumi S, Isobe H, Gemma A, Harada M, Yoshizawa H, Kinoshita I, et al: Gefitinib or chemotherapy for non-small-cell lung cancer with mutated EGFR. N Engl J Med 362: 2380-2388, 2010.

3. Mitsudomi T, Morita S, Yatabe Y, Negoro S, Okamoto I, Tsurutani J, Seto T, Satouchi M, Tada H, Hirashima T, et al: Gefitinib versus cisplatin plus docetaxel in patients with non-small-cell lung cancer harbouring mutations of the epidermal growth factor receptor (WJTOG3405): An open label, randomised phase 3 trial. Lancet Oncol 11: 121-128, 2010.
4. Inomata M, Hayashi R, Yamamoto A, Tokui K, Taka C, Okazawa S, Kambara K, Suzuki K, Ichikawa T, Yamada T, et al: Plasma neuron-specific enolase level as a prognostic marker in patients with non-small cell lung cancer receiving gefitinib. Mol Clin Oncol 3: 802-806, 2015.

5. Albain KS, Crowley JJ, LeBlanc M and Livingston RB: Survival determinants in extensive-stage non-small-cell lung cancer: The Southwest Oncology Group experience. J Clin Oncol 9: 1618-1626, 1991

6. Ulas A, Turkoz FP, Silay K, Tokluoglu S, Avci N, Oksuzoglu B and Alkis N: A laboratory prognostic index model for patients with advanced non-small cell lung cancer. PLoS One 9: e114471, 2014.

7. Koukourakis MI, Giatromanolaki A, Sivridis E, Bougioukas G, Didilis V, Gatter KC and Harris AL; Tumour Angiogenesis Research Group: Lactate dehydrogenase-5 (LDH-5) overexpression in non-small-cell lung cancer tissues is linked to tumour hypoxia, angiogenic factor production and poor prognosis. Br J Cancer 89: 877-885, 2003.

8. Danner BC, Didilis VN, Wiemeyer S, Stojanovic T, Kitz J, Emmert A, Füzesi L and Schöndube FA: Long-term survival is linked to serum LDH and partly to tumour LDH-5 in NSCLC. Anticancer Res 30: 1347-1351, 2010.

9. Seto T, Kato T, Nishio M, Goto K, Atagi S, Hosomi Y, Yamamoto N, Hida T, Maemondo M, Nakagawa K, et al: Erlotinib alone or with bevacizumab as first-line therapy in patients with advanced non-squamous non-small-cell lung cancer harbouring EGFR mutations (JO25567): An open-label, randomised, multicentre, phase 2 study. Lancet Oncol 15: 1236-1244, 2014. 